\title{
Gastroenteritis due to typhoidal Salmonella: a decade of observation at an urban and a rural diarrheal disease hospital in Bangladesh
}

Sumon Kumar Das ${ }^{1,2}$, Mohammod Jobayer Chisti ${ }^{1}$, Mokibul Hassan Afrad', Mohammad Abdul Malek',

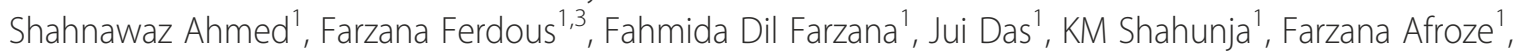
Mohammed Abdus Salam', Tahmeed Ahmed ${ }^{1}$, Abu Syed Golam Faruque ${ }^{1 *}$, Peter John Baker ${ }^{2}$ and Abdullah Al Mamun ${ }^{2}$

\begin{abstract}
Background: The study aimed to compare the socio-demographic, host and clinical characteristics, seasonality and antimicrobial susceptibility of Typhoidal Salmonella (Salmonella enterica serovar Typhi and Paratyphi) (TS) with diarrhea between urban and rural Bangladesh.

Methods: Relevant information of 77/25,767 (0.30\%) and 290/17,622 (1.65\%) patients positive with TS (in stool) were extracted from the data archive of Diarrheal Disease Surveillance System of icddr,b (urban Dhaka and rural Matlab Hospitals respectively) during 2000-2012. Comparison group (diarrhea patients negative for TS) was randomly selected from the database (1:3 ratio). Two poisson regression models were investigated for modelling seasonal effects on the number of cases.
\end{abstract}

Results: Salmonella Typhi was more frequently isolated in Dhaka than Matlab (57\% vs. 5\%, $p<0.001$ ); while Salmonella Paratyphi was more frequent in Matlab than Dhaka (96\% vs. 43\%; $p$ < 0.001). Fever [adj. OR-5.86 (95\% Cl: 2.16, 15.94)], antimicrobial use at home $[5.08(2.60,9.90)]$, and fecal red blood cells $[2.53(1.38,4.64)]$ were significantly associated with detection of TS in stool of patient from Dhaka. For Matlab, the correlates were, vomiting [1.88 $(1.35,2.64)]$, fecal macrophage $[1.89(1.29,2.74)]$ in addition to fever and duration of diarrhea and antimicrobial use. At Dhaka, all Salmonella Typhi isolates were susceptible to ceftriaxone; while in Dhaka and Matlab however, for ciprofloxacin it was $45 \%$ and $91 \%$, respectively. Susceptibility to chloramphenicol, ampicillin, trimethoprim-sulphamethoxazole and nalidixic acid ranged from 12\%-58\%. Salmonella Paratyphi were susceptible to ceftriaxone (99\%). A significant seasonal trend and year difference (before and after 2007) for Matlab was observed ( $p<0.001$ for all effects). Dhaka does not show significant year or seasonal effects ( $p=0.07$ for years and $p=0.81$ and $p=0.18$ for the cos and sin components, respectively). While not significant, two seasonal peaks were observed in Dhaka (January-February and September-November); while a single peak (August-November) was observed in Matlab.

Conclusions: Proportion of serovar distribution of TS and their clinical characteristics, antimicrobial susceptibility and seasonal pattern were different among diarrhea patients in urban Dhaka and rural Matlab of Bangladesh.

Keywords: Bangladesh, Diarrhea, Rural, Typhoidal Salmonella, Urban

\footnotetext{
* Correspondence: gfaruque@icddrb.org

${ }^{1}$ Centre for Nutrition and Food Security (CNFS), International Centre for Diarrhoeal Disease Research, Bangladesh (icddr,b), Dhaka, Bangladesh Full list of author information is available at the end of the article
} 


\section{Background}

Typhoid and paratyphoid fever may be associated with constipation, normal bowel habit or diarrhea. There is lack of reporting on gastroenteritis due to Salmonella enterica serovar Typhi (S. Typhi) and Paratyphi (S. Paratyphi) globally due to their lower incidence relative to illness caused by more frequent enteric pathogens such as rotavirus, Shigella, non-typhoidal Salmonella, Campylobacter jejuni, Escherichia coli and Vibrio cholerae in developing countries [1-5]. Both of these Salmonella serovars or typhoidal Salmonella (TS) cause enteric fever, which may be fatal if not adequately treated. Clinical description of non-typhoidal Salmonella (NTS) gastroenteritis, more common in developed countries, is available [6,7]; however, there is lack of published literatures on the clinical, host and socio-demographic characteristics of gastroenteritis due to typhoidal Salmonella. Moreover, the differences in the disease prevalence and outcome between urban and rural areas are not well investigated.

The International Centre for Diarrhoeal Disease Research, Bangladesh (icddr,b) maintains Diarrheal Disease Surveillance System (DDSS) at its urban Dhaka Hospital and rural Matlab Hospital [8]. The Dhaka Hospital is located at icddr,b's headquarter in Dhaka, the capital city of Bangladesh. This hospital systematically enrolls $2 \%$ (every $50^{\text {th }}$ ) of all patients in the DDSS since 1996 [9]. The Matlab Hospital enrolls all diarrheal patients coming from its Health and Demographic Surveillance System (HDSS) villages in rural Matlab, about 55 kilometers south-west of Dhaka. The DDSS collects demographic, clinical and laboratory information from the enrolled patients and maintains electronic databases by using identical data collection tools. In this study, we collected relevant information from these databases to assess the proportion of typhoidal Salmonella i.e. Salmonella enterica Typhi and Paratyphi, and compared the differences in aspect of the proportion and socio-demographic, clinical and host characteristics, seasonality and antimicrobial susceptibility patterns.

\section{Methods}

\section{Study design, source of data and sample framing}

A case-control study design had been employed. Individuals with positive stool culture for TS, with other enteric co-pathogens such as Vibrio cholerae, Shigella spp., Campylobacter, Escherichia coli, rotavirus, Entamoeba histolytica, and Giardia lamblia were considered as case irrespective of age, sex and socio-economic status. Randomly selected diarrheal patients without TS constituted the controls.

For this 13 year period (2000-2012) analyses, we extracted the relevant information from the data archive of DDSS of both urban Dhaka and rural Matlab Hospitals. During the study period, a total of 25,767 patients in
Dhaka and 17,622 in Matlab Hospital were enrolled in the surveillance system and $77(0.30 \%)$ and 290 (1.65\%) of them respectively has a positive stool culture for TS, including all other enteric co-pathogens (detailed distribution of these co-pathogens is listed in Table 1). These 77 and 290 patients constituted the case study population. Comparison groups were randomly selected as 1:3 (control) ratio to increase the power of the present analysis. Thus 231 and 870 individuals from Dhaka and Matlab were considered as comparison groups as diarrhea patients negative for TS. The patients of either sex, segregated into two age strata: 0 to 14 years of age and 15 years and above. Those who attended the hospital between the study periods were randomly selected as selection of age stratified controls.

\section{Lab methodology}

All patients coming from HDSS area in Matlab were included and their stool specimens were processed in the Matlab Microbiology Laboratory; a 2\% sub sample from Dhaka Hospital were examined in the central laboratory in Dhaka. Each specimen was aliquoted into three serial containers and submitted to the respective laboratories for routine screening of common enteric pathogens such as Salmonella spp. [10], Vibrio cholerae [11], Shigella spp. [10], Campylobacter [10], Escherichia coli [12], rotavirus [13], Entamoeba histolytica [10], and Giardia lamblia [10], isolated and identified using standard laboratory methods throughout the study period in both the site.

Susceptibility to antimicrobial agents was determined by the disk diffusion method as recommended by the Clinical Laboratory Standards Institute (CLSI 2010, June update) with commercial antimicrobial discs (Oxoid, Basingstoke, United Kingdom). The antibiotic discs used were; ampicillin $(10 \mu \mathrm{g})$, nalidixic acid $(30 \mu \mathrm{g})$, choleramphenecol $(30 \mu \mathrm{g})$, trimethoprim-sulfamethoxazole (TMP-SXT) $(25 \mu \mathrm{g})$, ciprofloxacin $(5 \mu \mathrm{g})$, and ceftriaxone $(30 \mu \mathrm{g})$ [14].

\section{Data analysis}

Data were analyzed using Statistical Package for Social Sciences (SPSS) Windows (Version 15.2; Chicago, IL) and Epi Info (Version 6.0, USD, Stone Mountain, GA). Proportional differences were compared by Chi-square test, and assessed strength of association by estimating odds ratios (OR) and 95\% confidence intervals (CI) around them. Two-sided alpha (probability) of $<0.05$ was considered to be statistically significant. Nutritional status (z-score for children under-5) was calculated using WHO-anthro 2005 software and malnutrition was defined as WHO guideline as $<-2.00 \mathrm{SD}$ [underweight (weightfor-age z-score), stunting (height-for-age z-score), wasting (weight-for-height z-score)] [15]. Site specific multivariate logistic regression analyses were also performed to determine the predictors of TS and variables identified to be 
Table 1 Distribution of co-infection with Typhoidal Salmonella and pathogens among diarrhea patients negative for TS

\begin{tabular}{|c|c|c|c|c|}
\hline \multirow[t]{2}{*}{ Pathogens } & \multicolumn{2}{|l|}{ Co-infection with TS } & \multicolumn{2}{|c|}{ Pathogen among diarrhea patients negative for TS } \\
\hline & Dhaka; $n=77$ (\%) & Matlab; $n=290(\%)$ & Dhaka; $n=231$ (\%) & Matlab; $\mathbf{n}=\mathbf{8 7 0}(\%)$ \\
\hline Vibrio cholerae 01 & $2(3)$ & $8(3)$ & $62(27)$ & $100(8)$ \\
\hline Vibrio cholerae 0139 & 0 & 0 & $2(1)$ & $7(1)$ \\
\hline Vibrio cholerae non 01 & 0 & $11(4)$ & 0 & $27(3)$ \\
\hline Shigella spp. & 0 & $10(3)$ & $11(5)$ & $86(10)$ \\
\hline Campylobacter spp. & $2(3)$ & $6(2)$ & $9(4)$ & $9(1)$ \\
\hline Aeromonas spp. & $2(3)$ & ND & 8 & ND \\
\hline Rotavirus & $10(13)$ & $28(10)$ & $55(24)$ & $123(14)$ \\
\hline Giardia lamblia & 0 & $4(1)$ & $6(3)$ & $25(3)$ \\
\hline Entamoeba histolytica & 0 & $3(1)$ & $1(0.4)$ & $6(1)$ \\
\hline
\end{tabular}

ND: not done.

independently associated ( $\mathrm{p}<0.05)$ (univariate analysis) with the outcome variable in each model. Variables which were age specific, for example malnutrition (underweight, stunting and wasting) among under-5 children, maternal and paternal education upto 14 years of age were not included, due to harmonizing the analysis in both the sites.

Two poisson regression models were investigated for modelling seasonal effects on the number of cases [16]. Firstly, a cosinor poisson regression model with year effects was fitted to both the monthly and daily time series at each site. Residual plots and diagnostics showed no evidence of autocorrelation. Both monthly and daily data revealed the same patterns with the effects having similar p-values so only the monthly models are presented here. Secondly, generalised additive models (GAM) with 5 and $6 \mathrm{df}$ per year were fitted to the daily time series at each site. However, while the model fits had similar AICs (Matlab: cosinor AIC $=2088$, GAM on 40 df AIC $=2082$ and Dhaka: cosinor AIC $=797$, GAM on $30 \mathrm{df}$ AIC $=808$ ), these models suffered from convergence problems and exhibited significant autocorrelation. Hence the simpler and more parsimonious cosinor models are presented. The models and residual diagnostics were carried out using the $R$ season package [16]. The monthly model was slightly over dispersed for Matlab due to excess zeros (Matlab: residual deviance $X^{2}=192.3$ on $141 \mathrm{df}$, Dhaka: 145.7 on $141 \mathrm{df}$ ) since we would expect the $X^{2}$ to be about equal to the $\mathrm{df}$ if there was no over dispersion.

\section{Ethical consideration}

The DDSS of icddr,b is a routine activity of the Dhaka and Matlab Hospitals, which have approval of both the Research Review Committee and Ethical Review Committee of icddr,b. Accordingly, verbal consent was taken from the adult patients and from the parents/ attending caregivers of the minors before their enrollment in the DDSS.

\section{Results and discussion}

Of all TS isolates, $S$. Typhi [57\% $(\mathrm{n}=44)$ vs. $5 \%(\mathrm{n}=12)$; $\mathrm{p}<0.001$ ] was higher in Dhaka as compared to Matlab site. Whereas, S. Paratyphi (A and B) [96\% $(\mathrm{n}=278)$ vs. $43 \%(\mathrm{n}=33) ; \mathrm{p}<0.001$ ] was more frequently isolated in the Maltab in contrast to Dhaka population.

Of all TS isolates from Dhaka individuals 0-14 years old, S. Typhi represented $67 \%$ of the isolates $(n=26 / 39)$ and $S$. Paratyphi represented $33 \%(n=13 / 39)$. Conversely, for Maltab it was $4 \%(n=5 / 116)$ and $96 \%(n=111 / 116)$ respectively. Among 15 years and above individuals, the prevalence was $47 \%(n=18 / 38)$ and $53 \%(n=20 / 38)$ in Dhaka, and $4 \%(\mathrm{n}=7 / 174)$ and $96 \%(\mathrm{n}=167 / 174)$ in Maltab respectively.

Half of the TS positive individuals were aged 0-14 years in Dhaka and overall 56\% were male. A significantly higher proportion of individuals with TS had vomiting, some to severe dehydration, fever, duration of diarrhea more than 1 day before admission to the hospital, use of antimicrobials at home, and presence of fecal red blood cells compared to their control group. However, a lower proportion of them needed to use intravenous saline for rehydration. A higher proportion were malnourished (underweight, stunting and wasting) (Table 2). In the multivariate analysis, after controlling for the confounders, TS gastroenteritis was significantly associated with fever, use of antimicrobials at home, and fecal red blood cells in Dhaka (Table 2).

In Matlab, a significantly higher proportion of TS individuals had vomiting, fever, longer duration of diarrhea (more than 1 day before admission to the hospital), use of antimicrobials at home, and higher number of fecal red blood cells, leucocytes and macrophage compared to control group. However, they needed less intravenous saline compared to Dhaka and exhibited a lesser number of red blood cells in stool (Table 3). In multivariate analysis, only fever, vomiting, longer duration of diarrhea, use of antimicrobials and fecal macrophage at home 


\begin{tabular}{|c|c|c|c|c|}
\hline Characteristic & TS $n=77(\%)$ & $\begin{array}{l}\text { Diarrhea patients negative } \\
\text { for TS } n=231(\%)\end{array}$ & $\begin{array}{l}\text { Unadjusted OR } \\
(95 \% \mathrm{Cl}) \mathrm{p} \text { value }\end{array}$ & $\begin{array}{c}\text { Adjusted OR } \\
(95 \% \mathrm{Cl}) \mathrm{p} \text { value }\end{array}$ \\
\hline Male sex & $43(56)$ & $129(56)$ & $1.00(0.58,1.74) 0.8$ & - \\
\hline Age stratum & & & & - \\
\hline $0-14$ years & $39(51)$ & $117(51)$ & $1.00(0.58,1.73) 0.8$ & - \\
\hline 15 years and above & $38(49)$ & $114(49)$ & - & - \\
\hline Maternal illiteracy & $21 / 39(54)$ & $35 / 117(30)$ & $2.73(1.22,6.15) 0.012$ & - \\
\hline Paternal illiteracy & 19/39 (49) & $40 / 117(34)$ & $1.83(0.82,4.07) 0.1$ & - \\
\hline $\begin{array}{l}\text { Poor socio-economic status (median monthly } \\
\text { family income }<\text { US\$115) }\end{array}$ & $46(60)$ & $119(52)$ & $1.40(0.80,2.44) 0.2$ & - \\
\hline Use of non-sanitary toilet & $23(30)$ & $0(0)$ & - & - \\
\hline H/o abdominal pain & $35(46)$ & $100(43)$ & $1.09(0.63,1.89) 0.8$ & - \\
\hline $\mathrm{H} / \mathrm{O}$ vomiting in the last 24 hours & $63(82)$ & $164(71)$ & $1.84(0.93,3.70) 0.085$ & - \\
\hline Fever (Temperature $\geq 37.8^{\circ} \mathrm{C}$ ) & $13(17)$ & $9(4)$ & $5.01(1.90,13.41)<0.001$ & $5.86(2.16,15.94) 0.001$ \\
\hline Watery stool (lack of mucus/blood) & $74(96)$ & $219(95)$ & $1.35(0.34,6.21) 0.7$ & - \\
\hline Dehydration (moderate/severe) & $52(68)$ & $149(65)$ & $1.14(0.64,2.06) 0.7$ & - \\
\hline Duration of diarrhea (>1 day) & $50(65)$ & $105(46)$ & $2.22(1.26,3.93) 0.004$ & $1.27(0.66,2.46) 0.5$ \\
\hline Hospital stay of $\geq 24$ hours & $31(40)$ & $84(36)$ & $1.18(0.67,2.07) 0.6$ & - \\
\hline Use of IV rehydration & $19(25)$ & $92(40)$ & $0.49(0.27,0.92) 0.023$ & $0.72(0.36,1.46) 0.368$ \\
\hline Use of antimicrobial at home & $58(75)$ & $85(37)$ & $5.24(2.82,9.81)<0.001$ & $5.08(2.60,9.90)<0.001$ \\
\hline Wasting ( $<5$ years) & $13 / 30(43)$ & $22 / 103(21)$ & $2.82(1.09,7.27) 0.030$ & - \\
\hline Stunting ( $<5$ years) & $16 / 30(53)$ & $26 / 103(25)$ & $3.16(1.27,7.90) 0.011$ & - \\
\hline Underweight ( $<5$ years) & $21 / 30(70)$ & $34 / 103(33)$ & $4.74(1.82,12.62) 0.006$ & - \\
\hline Fecal red blood cell/hpf ( 1 to $>50)$ & $33(43)$ & $67(29)$ & $1.84(1.04,3.24) 0.035$ & $2.53(1.38,4.64) 0.003$ \\
\hline Fecal leukocytes/hpf ( 11 to $>50)$ & $37(48)$ & $96(42)$ & $1.30(0.75,2.26) 0.3$ & - \\
\hline Fecal macrophage/hpf (1 to 10 ) & $22(29)$ & $45(20)$ & $1.65(0.88,3.11) 0.1$ & - \\
\hline
\end{tabular}

remained significantly associated with TS in addition to poor socioeconomic status (Table 3).

The monthly data clearly exhibits a significant seasonal trend for Matlab and a significant difference between years ( $\mathrm{p}<0.001$ for all effects). Dhaka does not show significant year or seasonal effects $(p=0.07$ for years and $\mathrm{p}=0.81$ and $\mathrm{p}=0.18$ for the cos and sin components, respectively). Two seasonal peaks of TS were observed in Dhaka- during the months of January and February, and August to November in Dhaka, but a single peak in Matlab that corresponded to the later peak in Dhaka field site (Figure 1) but these were not significant.

All $S$. Typhi isolates were susceptible to ceftriaxone in Dhaka and Matlab. For ciprofloxacin it was $45 \%$ vs. $91 \%$ respectively, while at least $52 \%$ of the isolates were susceptible to chloramphenicol at both sites. Susceptibility to ampicillin, trimethoprim-sulfamethoxazole and nalidixic acid ranged from $12 \%$ to $58 \%$ in the study areas (Figure 2). On the other hand, for $S$. Paratyphi, 99\% were susceptibility to ceftriaxone in both the sites. Susceptibility patterns of other antimicrobials were shown in Figure 2.
Given the absence of information in medical literature, we assumed that the clinical and socio-demographic features of TS associated gastroenteritis might not differ by place of residence - urban Dhaka and rural Maltab as well as diarrhea due to other pathogens. However, we observed a number of important differences, which are likely to have public health implications. Among the differences, the prevalence of $S$. Typhi was higher and that of Paratyphi was lower in Dhaka compared to Matlab.

There are differences between Dhaka and Matlab populations with regards to food, water and hygiene practices. They all have significant associations with gastroenteritis irrespective of age, sex and socio-demographic contexts [17]. Most of the recent studies have described the features of gastroenteritis due to NTS but only a few described urban-rural (Dhaka-Matlab) differentials [7]. The present study might be the novel one to describe geographical heterogeneity of TS gastroenteritis irrespective of their age stratum. Increasing trend of $S$. Paratyphi was reported in rural areas and mostly associated with poor sanitation and socio-economic condition with lack of safe 


\begin{tabular}{|c|c|c|c|c|}
\hline Characteristic & TS $n=290(\%)$ & $\begin{array}{l}\text { Diarrhea patients negative } \\
\text { for TS } n=870(\%)\end{array}$ & $\begin{array}{l}\text { Unadjusted OR } \\
(95 \% \mathrm{Cl}) \mathrm{p} \text { value }\end{array}$ & $\begin{array}{l}\text { Adjusted OR } \\
(95 \% \mathrm{Cl}) \mathrm{p} \text { value }\end{array}$ \\
\hline Male sex & $161(56)$ & $440(51)$ & $1.22(0.93,1.61) 0.1$ & - \\
\hline Age stratum & & & & - \\
\hline $0-14$ years & $116(40)$ & $348(40)$ & $1.00(0.76,1.32) 0.9$ & - \\
\hline 15 years and above & $174(60)$ & $552(60)$ & - & - \\
\hline Maternal illiteracy & $25 / 116(22)$ & 65/348 (19) & $1.20(0.69,2.07) 0.5$ & - \\
\hline Paternal illiteracy & $27 / 116(23)$ & $84 / 348(24)$ & $0.95(0.56,1.61) 0.9$ & - \\
\hline $\begin{array}{l}\text { Poor socio-economic status (median monthly } \\
\text { family income }<\text { US\$115) }\end{array}$ & $168(58)$ & $467(54)$ & $1.19(0.90,1.57) 0.2$ & - \\
\hline Use of non-sanitary toilet & $245(85)$ & $0(0)$ & $<0.001(0.00)<0.001$ & - \\
\hline H/o abdominal pain & $158(55)$ & $440(51)$ & $1.17(0.89,1.54) 0.2$ & - \\
\hline $\mathrm{H} / \mathrm{O}$ vomiting in the last 24 hours & $219(76)$ & $570(66)$ & $1.62(1.19,2.22) 0.002$ & $1.88(1.35,2.64)<0.001$ \\
\hline Fever (Temperature $\geq 37.8^{\circ} \mathrm{C}$ ) & $100(35)$ & $128(15)$ & $3.05(2.22,4.19)<0.001$ & $22.90(2.08,4.06)<0.001$ \\
\hline Watery stool (lack of mucus/blood) & $237(82)$ & $692(80)$ & $1.15(0.81,1.64) 0.4$ & - \\
\hline Dehydration (moderate/severe) & $152(52)$ & $417(48)$ & $1.20(0.91,1.58) 0.2$ & - \\
\hline Duration of diarrhea (>1 day) & $155(53)$ & $317(36)$ & $2.00(1.52,2.64)<0.001$ & $1.78(1.30,2.44)<0.001$ \\
\hline Hospital stay of $\geq 24$ hours & $148(51)$ & $407(47)$ & $1.19(0.90,1.56) 0.2$ & - \\
\hline Use of IV rehydration & $50(17)$ & $210(24)$ & $0.65(0.46,0.93) 0.018$ & $0.74(0.50,1.09) 0.124$ \\
\hline Use of antimicrobial at home & $158(55)$ & $211(24)$ & $3.74(2.88,4.99)<0.001$ & $3.15(2.33,4.27)<0.001$ \\
\hline Wasting ( $<5$ years) & 28/95 (30) & $73 / 319(23)$ & $1.41(0.82,2.42) 0.2$ & - \\
\hline Stunting ( $<5$ years) & 31/95 (33) & $101 / 319(32)$ & $1.05(0.62,1.75) 0.9$ & - \\
\hline Underweight ( $<5$ years) & $32 / 95(34)$ & $125 / 320(40)$ & $0.79(0.48,1.32) 0.4$ & - \\
\hline Fecal red blood cell/hpf ( 1 to $>50)$ & $207(71)$ & $508(58)$ & $1.78(1.32,2.40)<0.001$ & $1.11(0.67,1.82) 0.7$ \\
\hline Fecal leukocytes/hpf ( 11 to $>50)$ & $241(83)$ & $630(72)$ & $1.87(1.31,2.68)<0.001$ & $1.44(0.87,2.39) 0.2$ \\
\hline Fecal macrophage/hpf (1 to 10 ) & $151(52)$ & $285(33)$ & $2.23(1.69,2.95)<0.001$ & $1.89(1.29,2.74) 0.001$ \\
\hline
\end{tabular}

drinking water $[18,19]$. Although, tube-well is considered as a safe source of drinking water in rural Matlab, sanitation facility in this rural catchment area is still very poor; this might explain the increased isolation rate of $S$. Paratyphi.

It was observed that, higher illiteracy rates among parents of Dhaka children with TS gastroenteritis. Literacy is an important factor for child care, proper feeding and sanitation practices including health care seeking behavior, leading to higher rates of malnutrition (underweight) in children from Dhaka than their Matlab counterparts [20]. This finding correlated with presence of vomiting with more dehydrating diarrhea [20]. On the other hand, malnutrition-associated altered immune status [21] might predict the susceptibility of infection with Salmonella. A high proportion of patients attending the Dhaka Hospital had received antimicrobials at home, which could explain higher rates of resistance to more commonly used oral antimicrobials relative to Matlab; access to health facilities and pharmacy in Dhaka may explain higher use and higher resistance. Lesser use of non-sanitary toilets is likely related to the availability of modern sewerage system, although contamination of supply water by sewerage leaks is believed to be common which may lead to outbreaks for enteric infections.

Presence of fecal inflammatory cells is an expected finding due to invasive nature of the pathogens. Salmonella is usually transmitted by fecal-oral route due to consumption of contaminated food or drinks, and organisms invade the intestinal mucosa leading to a disease by interaction with reticulo-endothelial system [22]. All of them were found statistically significant for Matlab model. However, only fecal red blood cell was significant for Dhaka. It might be due to the virulence properties of the pathogen or relative compromised nutrition among rural patients may explain better host defense including better inflammatory response and higher number of inflammatory cells. This is supported by higher proportion of Matlab individuals presenting with fever and their longer hospitalization.

An urban-rural differential was also observed in seasonality. There were rising seasonal effects at Matlab 


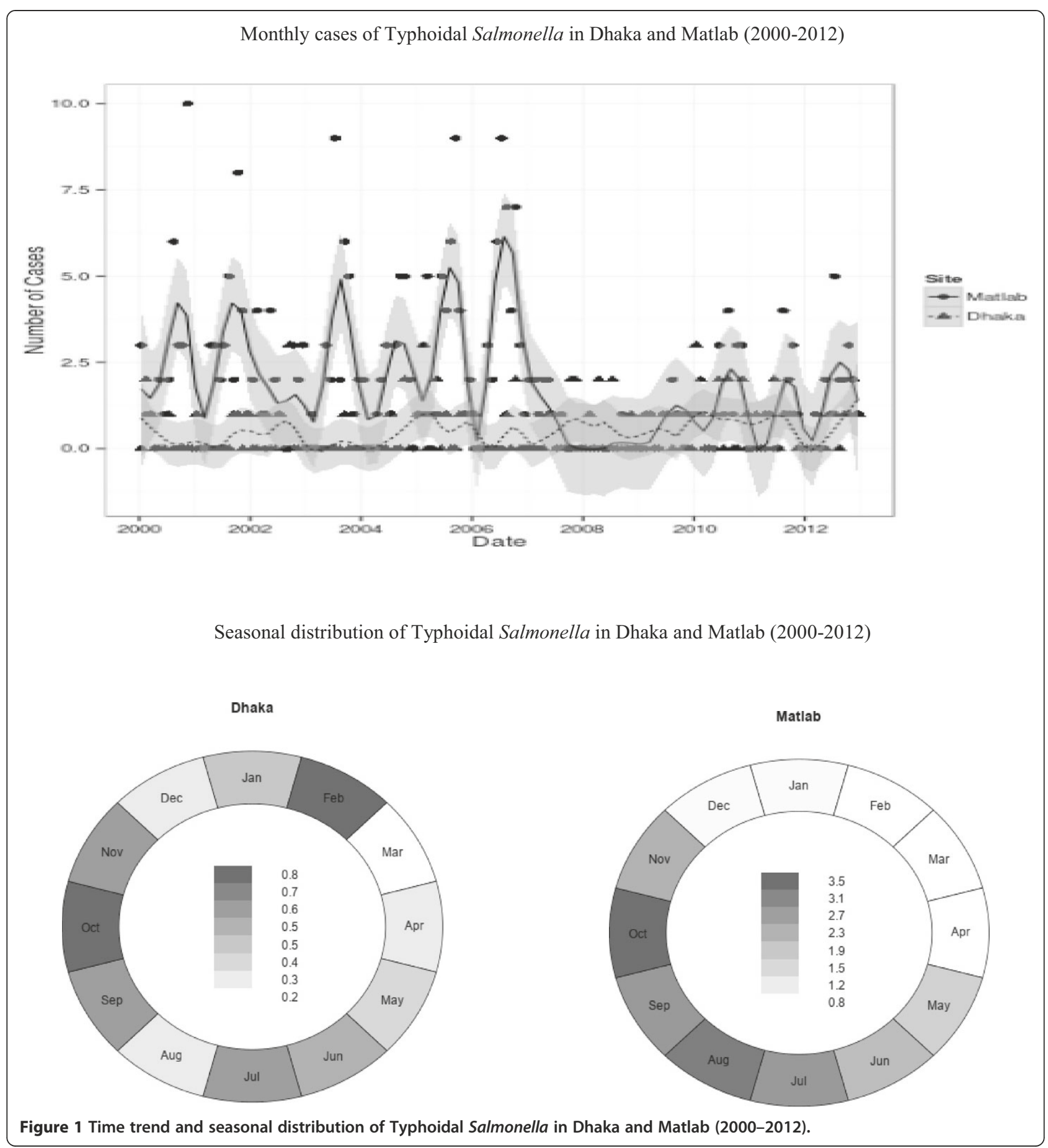

$(\mathrm{p}<0.001)$ but no significant effects were seen at Dhaka. In addition to a common seasonal peak later in the year, a peak was also observed in urban Dhaka early in the year of winter months of January and February. Seasonal upsurges of pathogen is well documented elsewhere for other common diarrheal pathogens such as rotavirus [23], Vibrio cholerae [24] or Shigella [25,26]. Several environmental as well as host characteristics may explain underlying predictions $[27,28]$. Moreover, for Matlab, there appears to be a significant decrease around 2007 and we do not have any ready explanation for such reduction.

\section{Limitations}

The present study was conducted among people attending diarrheal disease facilities, and may not be representative of the general population. The number of cases in Dhaka was very small which resulted in a diminished 

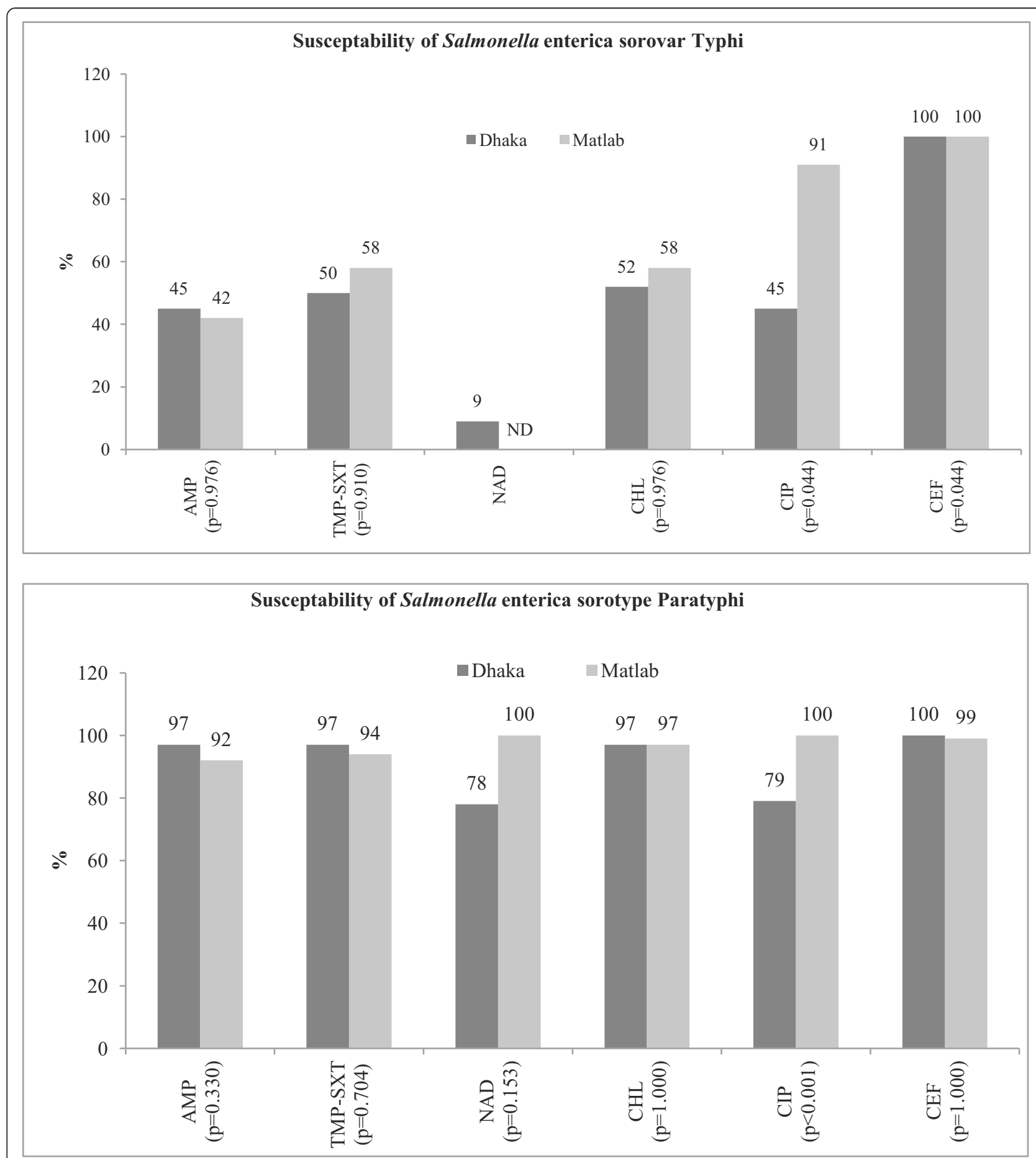

Figure 2 Antimicrobial susceptibility of Typhoidal Salmonella in urban and rural sites (2000-2012).

ability to detect seasonal differences. For Matlab, while more cases were seen, a high proportion of zeros was observed. While this caused convergence problems for the GAM model a cosinor poisson regression model with year effects fitted the data reasonably well and so zero inflated possion models were not necessary. However; in both the facilities, cost-free treatment is provided and it is accessible to all people, irrespective of their socioeconomic or other background, increasing the likelihood of including individuals with low socioeconomic status. Other strengths were the systematic unbiased sampling, large sample size of the study participants from surveillance system, and high quality laboratory performance further added to the strengths. 


\section{Conclusion}

Distinct geographical variations were observed with regard to socio-demographic and clinical characteristics among individuals with gastroenteritis due to TS between urban and rural areas.

\section{Abbreviation}

AMP: Ampicillin; CEF: Ceftriaxone; CHL: Chloramphenocol; Cl: Confidence intervals; CIP: Ciprofloxacin; DDSS: Diarrhoeal disease surveillance system; HDDS: Health and demographic surveillance system; icddr,b: International centre for diarrhoeal disease research, Bangladesh; ND: Not done; NAD: Nalidixic acid; NTS: Non-typhoidal Salmonella; OR: Odds ratios; SPSS: Statistical package for social sciences; S. Typhi: Salmonella enterica serover Typhi; S. Paratyphi: Salmonella enterica serover and Partyphi; TMP-STX: Trimethoprim-sulfamethoxazole: TS: Typhoidal Salmonella.

\section{Competing interests}

The authors declare that they have no competing interests.

\section{Authors' contributions}

SKD, MJC, MAM, ASGF, JD, MAS, PJB, AAM- have made substantial contributions to conception and design, or acquisition of data, or analysis and interpretation of data; SKD, MJC, SH, FF, FDF -have been involved in drafting the manuscript; $\mathrm{TH}, \mathrm{MHA}, \mathrm{FA}, \mathrm{MJC}, \mathrm{MAS}, \mathrm{SH}, \mathrm{FF}, \mathrm{FDF}, \mathrm{JD}, \mathrm{PJB}, \mathrm{AAM}$ - revised it critically for important intellectual content; ASGF, TH, MJC, SKD-have given final approval of the version to be published. Each author has participated sufficiently in the work to take public responsibility for appropriate portions of the content. All authors have read and approved the final manuscript.

\section{Acknowledgements}

Hospital surveillance was funded by icddr,b and the Government of the People's Republic of Bangladesh through IHP-HNPRP. icddr,b acknowledges with gratitude the commitment of the Government of the People's Republic of Bangladesh to icddr,b's research efforts. icddr,b also gratefully acknowledges the following donors who provided unrestricted support to it's research efforts during the project's life: Australian Agency for International Development (AusAID), Government of the People's Republic of Bangladesh, Canadian International Development Agency (CIDA), Embassy of the Kingdom of the Netherlands (EKN), Swedish International Development Cooperation Agency (Sida), Swiss Agency for Development and Cooperation (SDC), and Department for International Development, UK (DFID).

\section{Author details}

${ }^{1}$ Centre for Nutrition and Food Security (CNFS), International Centre for Diarrhoeal Disease Research, Bangladesh (icddr,b), Dhaka, Bangladesh. ${ }^{2}$ School of Population Health, The University of Queensland, Brisbane, Australia. ${ }^{3}$ Department of Clinical Trial and Clinical Epidemiology, Graduate School of Comprehensive Human Sciences, University of Tsukuba, Tsukuba, Ibaraki, Japan.

\section{Received: 15 August 2013 Accepted: 30 July 2014}

Published: 7 August 2014

\section{References}

1. Shah D, Choudhury P, Gupta P, Mathew JL, Gera T, Gogia S, Mohan P, Panda R, Menon S: Promoting appropriate management of diarrhea: a systematic review of literature for advocacy and action: UNICEF-PHFI series on newborn and child health. India Indian Pediatr 2012, 49(8):627-649.

2. Dennehy PH: Rotavirus infection: an update on management and prevention. Adv Pediatr 2012, 59(1):47-74

3. Shakoor S, Zaidi AK, Hasan R: Tropical bacterial gastrointestinal infections. Infect Dis Clin North Am 2012, 26(2):437-453.

4. Sigman M, Luchette FA: Cholera: something old, something new. Surg Infect (Larchmt) 2012, 13(4):216-222.

5. Harris JB, LaRocque RC, Qadri F, Ryan ET, Calderwood SB: Cholera. Lancet 2012, 379(9835):2466-2476.

6. Shkalim V, Amir A, Samra Z, Amir J: Characteristics of non-typhi Salmonella gastroenteritis associated with bacteremia in infants and young children Infection 2012, 40(3):285-289.
7. Leung DT, Das SK, Malek MA, Ahmed D, Khanam F, Qadri F, Faruque AS, Ryan ET: Non-typhoidal Salmonella gastroenteritis at a diarrheal hospital in Dhaka, Bangladesh, 1996-2011. Am J Trop Med Hyg 2013, 88(4):661-669.

8. Das SK, Chisti MJ, Huq S, Malek MA, Salam MA, Ahmed T, Faruque ASG: Etiology of Diarrhea among Severely Malnourished Infants and Young Children: Observation of Urban-rural Differences over One Decade in Bangladesh. Food and Nutrition Sciences 2013, 4(3):233-239.

9. Stoll BJ, Glass Rl, Huq Ml, Khan MU, Holt JE, Banu H: Surveillance of patients attending a diarrhoeal disease hospital in Bangladesh. Br Med $J$ (Clin Res Ed) 1982, 285(6349):1185-1188.

10. WHO: Programme for control of diarrheal disease. In Manual for laboratory investigation of acute enteric infections. Geneva, Switzerland: World Health Organization; 1987.

11. Qadri F, Khan Al, Faruque AS, Begum YA, Chowdhury F, Nair GB, Salam MA Sack DA, Svennerholm AM: Enterotoxigenic Escherichia coli and Vibrio cholerae diarrhea, Bangladesh, 2004. Emerg Infect Dis 2005, 11(7):1104-1107.

12. Qadri F, Das SK, Faruque AS, Fuchs GJ, Albert MJ, Sack RB, Svennerholm AM: Prevalence of toxin types and colonization factors in enterotoxigenic Escherichia coli isolated during a 2-year period from diarrheal patients in Bangladesh. J Clin Microbiol 2000, 38(1):27-31.

13. Rahman M, De Leener K, Goegebuer T, Wollants E, Van der Donck I, Van Hoovels L, Van Ranst M: Genetic characterization of a novel, naturally occurring recombinant human G6P[6] rotavirus. J Clin Microbiol 2003, 41(5):2088-2095.

14. Clinical and laboratory standards Institute (CLSI): Performance standard for antimicrobial susceptibility testing: Twentieth Informational Suppliment. 30th edition. PA, USA: M100-S20; 2010.

15. Onyango AW, de Onis M: Traning course on child growth assessment: WHO child growrh standards. Geneva: WHO; 2008.

16. Barnett AG, Dobson AJ: Analysing Seasonal Health Data. Springer-Verlag Berlin Heidelberg: Springer; 2010.

17. Cairncross S, Hunt C, Boisson S, Bostoen K, Curtis V, Fung IC, Schmidt WP: Water, sanitation and hygiene for the prevention of diarrhoea. Int $J$ Epidemiol 2010, 39(Suppl 1):i193-i205.

18. Kanungo S, Dutta S, Sur D: Epidemiology of typhoid and paratyphoid fever in India. J Infect Dev Ctries 2008, 2(6):454-460.

19. Palit A, Ghosh S, Dutta S, Sur D, Bhattacharya MK, Bhattacharya SK: Increasing prevalence of Salmonella enterica serotype Paratyphi-A in patients with enteric fever in a periurban slum setting of Kolkata. India Int J Environ Health Res 2006, 16(6):455-459.

20. Chisti MJ, Hossain MI, Malek MA, Faruque AS, Ahmed T, Salam MA Characteristics of severely malnourished under-five children hospitalized with diarrhoea, and their policy implications. Acta Paediatr 2007, 96 (5):693-696.

21. Rodriguez L, Cervantes E, Ortiz R: Malnutrition and gastrointestinal and respiratory infections in children: a public health problem. Int J Environ Res Public Health 2011, 8(4):1174-1205.

22. Pegues DA, Miller Al: Salmonellosis. In Harrison, s Principals of internal medicine 17th edition. Edited by Fauci SA, Braunwald E, Kasper DL, Hauser SL, Longo DL, Jameson JL, Loscalzo J. New York, USA: McGraw-Hill education; 2008.

23. Patel MM, Pitzer VE, Alonso WJ, Vera D, Lopman B, Tate J, Viboud C, Parashar UD: Global seasonality of rotavirus disease. Pediatr Infect Dis $J$ 2013, 32(4):e134-e147.

24. Emch M, Feldacker C, Islam MS, Ali M: Seasonality of cholera from 1974 to 2005: a review of global patterns. Int J Health Geogr 2008, 7:31.

25. lushina Zh V: The seasonality of Flexner dysentery among preschoolers. Zh Mikrobiol Epidemiol Immunobiol 1993, 6:34-35.

26. Iushina $\mathrm{Zh} \mathrm{V}$ : The seasonality of Sonne dysentery among preschoolers. Zh Mikrobiol Epidemiol Immunobiol 1994, 6:53-54.

27. Sumi A, Rajendran K, Ramamurthy T, Krishnan T, Nair GB, Harigane K, Kobayashi $\mathrm{N}$ : Effect of temperature, relative humidity and rainfall on rotavirus infections in Kolkata, India. Epidemiol Infect 2013, 141(8):1652-1661.

28. Islam MS, Sharker MA, Rheman S, Hossain S, Mahmud ZH, Uddin AM, Yunus M, Osman MS, Ernst R, Rector I, Larson CP, Luby SP, Endtz HP, Cravioto A: Effects of local climate variability on transmission dynamics of cholera in Matlab, Bangladesh. Trans R Soc Trop Med Hyg 2009, 103(11):1165-1170.

doi:10.1186/1471-2334-14-435

Cite this article as: Das et al: Gastroenteritis due to typhoidal Salmonella: a decade of observation at an urban and a rural diarrheal disease hospital in Bangladesh. BMC Infectious Diseases 2014 14:435. 